\title{
"CADA PERSONA TIENE DERECHO A ESTAR DONDE SU CORAZÓN ESTÁ" MATERNAR UNA FAMILIA TRANSNACIONAL
}

\author{
Amarela Varela HUERTA ${ }^{1}$ \\ Ana Laura LÓPEZ ${ }^{2}$
}

\begin{abstract}
RESUMEN: Este artículo gira en torno a tres preguntas eje o disparadoras. Construimos esta etnografía en clave de autorepresentacional radical para explorar ¿cómo se autorrepresenta una mujer migrante, madre, atravesada por el gobierno global de fronteras? ¿Qué discursos, prácticas y dispositivos de gubernamentalidad migratoria, pero también de género y raciales, operan para heterorrepresentar las maternidades en familias transnacionales? Y, finalmente, ¿̇en qué sentido estas dos lógicas de representación performan nuevas formas de ejercer el trabajo de la maternidad y la crianza? En este artículo presentamos una reflexión feminista sobre las mujeres migrantes que buscan "una vida que se pueda vivir" en el sistema migratorio México-Estados Unidos.
\end{abstract}

PALABRAS CLAVE: familias trasnacionales; mujeres migrantes; deportación; autorrepresentación; autoetnografía.

\footnotetext{
1 Universidad Autónoma de la Ciudad de México. Profesora/investigadora en la Academia de Comunicación y Cultura. Aprendiz de feminista que apuesta por coproducir crónicas sobre luchas migrantes (y prácticas de muerte en su contra) narradas desde la experiencia y los saberes de los propios pueblos en movimiento. https://uacm. academia.edu/AmarelaVarela. Ha publicado el libro "Por el derecho a permanecer y a pertenecer, una sociología de la lucha de los migrantes" (Traficantes de Sueños, Madrid; 2013) y coordinado junto con Sandro Mezzadra y Blanca Cordero el libro colectivo "América Latina en movimiento" (traficantes de sueños, 2019) y con Alejandra Aquino y Fred Decossé un volumen colectivo "Desafiando fronteras. Control de la movilidad y experiencias migratorias en el contexto capitalista" (Frontera Press Oaxaca. 2013). Ha publicado artículos académicos en revistas indexadas y de divulgación científica. ORCID: https://orcid.org/0000-0001-8833-1143. amarela.varela@uacm.edu.mx.

2 Ana Laura López es madre transnacional, activista por los derechos de los migrantes y fundadora de colectivos y organizaciones de deportados y deportadas en México como Deportados Unidos en la Lucha. Desde su deportación en 2016 por parte del gobierno de Obama y Biden, Ana Laura materna a distancia, ahora de este lado del muro, a 2 jóvenes en Chicago y es madre y abuela de otros 4 jóvenes en México. Desde 2018 fundó y sostiene la empresa de diseño y estampado Deportados Brand. Es un ejemplo de lucha y resistencia que encarna en su historia y vida cotidiana el feminismo migrante realmente existente. deportadosunidosenlalucha@gmail.com.
} 


\section{"EACH PERSON HAS THE RIGHT TO BE WHERE THEIR HEART IS." MOTHERING A TRANSNATIONAL FAMILY}

ABSTRACT: This article examines three central questions. We build this ethnography based on the concept of radical self-representation to explore how a migrant woman, mother whose life is profoundly affected by system of global governance of borders, represents herself? What discourses, practices and mechanisms of migratory governance control, but also systems of gender and racial contol, operate to heterorepresent maternity in transnational families? And, finally, in what sense do these two logics of representation perform new ways of exercising the work of motherhood and parenting? In this article we present a feminist reflection on migrant women seeking "a life that can be lived" in the United States-Mexico immigration system.

KEYWORDS: transnational families; migrant women; deportation; self-representation; autoethnography.

\section{Introducción}

Partimos de la premisa de que lo novedoso en lo contemporáneo no son los desplazamientos humanos, ya que estos nos constituyen como especie, sino las formas de gobernar las fronteras, ancladas en un abierto odio racial contra migrantes, refugiados y desplazados. De ese modo nos interesó reflexionar en torno al trabajo de la imaginación sociológica para comprender las políticas de identidad que se ponen en juego, como un constructo político a la vez que subjetivo y cultural, contextual. De ahí que, con este trabajo buscamos abonar pistas comprensivas y explicativas sobre las transformaciones de la subjetividad femenina en movimiento: las migrantes, las desplazadas, las refugiadas, las deportadas desde este subcampo interdisciplinar de la sociología y la antropología contemporáneas.

En este artículo presentamos un corte de caja de una investigación de largo aliento en torno a las mujeres que han migrado por razones económicas o huyendo de diferentes formas de violencia para preservar su vida. Mostramos cómo, por dicho desplazamiento, se reconfiguran no solo las subjetividades de quienes ejercen la "fuga" (MEZZADRA, 2004), sino las estructuras sociales como la pareja, la familia y la comunidad de la que salieron o a la que fueron regresadas de forma forzada desde el país donde lograron establecerse para conseguir una vida que se pueda vivir. Las mujeres migrantes se transforman 
a sí mismas con la movilidad que ejercen, sino que sus "fugas" provocan también profundos cambios sociales en los territorios donde nacieron y en los que consiguen residir, trabajar y, a veces, amar y ser amadas., territorios de instalación desde donde estas mujeres migrantes envianremesas, al mismo tiempo que extrañan, echan de menos, a los hijos, las madres, las montańas y los cielos en los que crecieron, dirían en Brasil, tienen una vida permeada de una permanente saudage.

Como acompañante (la etnógrafa), o como organizadora comunitaria (la protagonista de este texto) de diferentes formas de luchas migrantes para lograr, primero, la subjetividad política y jurídica (los papeles) y, con ello, el derecho a tener derechos, hemos encontrado en nuestro caminar etnográfico a mujeres de muchas latitudes que, además de los derechos en el espacio público, se ven obligadas a reclamar el liderazgo de las luchas que construyen con otros varones migrantes.

Pero, al mismo tiempo, tal como sucedió con la protagonista de este texto, muchas mujeres que migran desempeñan un agenciamiento político que cambia las narrativas de autorrepresentación. Esto genera cambios radicales en las prácticas con mujeres que se desenvuelven en sus núcleos familiares de origen y también en las formas en las que deciden habitar su cotidiano en el exilio. En la fuga hay como recompensa libertad, transformación, autodeterminación.

En las migraciones y el desplazamiento (casi siempre forzado) las mujeres de los sures del mundo suelen atravesar violencias extremas en el tránsito. Y en las sociedades donde consiguen instalarse soportan relaciones de poder atravesadas por el racismo y el sexismo. No obstante, migrar también transforma su autopercepción, su "conciencia de sî", la idea que que Michel Foucault trabajó como "cuidado de sí", como práctica de libertad en sus textos de Hermenéutica del sujeto (FOUCAULT, 2001) y El sujeto y el poder (FOUCAULT, 1988) para pensar las estrategias de les sujetos para desujetarse de las mallas del poder. Desde nuestra perspectiva, lo pensando por el teórico del biopoder en relación a prácticas de libertad opera cuando las mujeres migramos o nos fugamos. ${ }^{3}$

Como consecuencia pues de estos agenciamientos, se transforman poco a poco las heterorrepresentaciones con las que son interpretadas en las tramas familiares, comunitarias y sociales que dejaron. Al mismo tiempo se transmutan las formas en cómo sus presencias son incorporadas a las narrativas de las sociedades que habitan en calidad de migradas.

\footnotetext{
3 Agradezco sinceramente a Sonia Rangel la conversación en torno al cuidado de sí como concepto foucoultiano que me ayudó a pensar con densidad esta hipótesis.
} 
Por eso nos parece fundamental abordar las migraciones de mujeres con una mirada abiertamente feminista e interseccional (VIVEROS, 2016; GOLUBOV, 2018), desde la óptica de las "políticas de identidad” (LOAÉZA REYES; CASTANEDA, 2014). Eso nos permite re/conocer en qué sentido provocan duelos y adolescencias. Ayuda a comprender cómo las migraciones permiten mutaciones en el juego de la hetero/autorrepresentación de las sujetas migrantes y los roles sociales asignados a su feminidad en los lugares que habitan y en los que dejaron.

Mirar con los lentes de la antropología cultural — que piensa las identidades individuales y colectivas, estructural e históricamente situadas - la migración de las mujeres en lo contemporáneo, permite vislumbrar las transformaciones de los imaginarios colectivos sobre los roles socialmente asignados a ese género.

En el siguiente apartado de este trabajo abordamos las preguntas motor que inspiran este ejercicio de interpretación. En un tercer apartado, y una vez comprendido el encuadre de la experiencia migrante que da cuerpo a este artículo, presentamos la autoetnografía de Ana Laura López, mujer mexicana, madre, migrante, deportada y feminista antirracista. Su trayectoria vital y política ayuda a explicar las nuevas formas de ciudadanía (VALENCIA, 2018) ${ }^{4}$ que ejercen las mujeres migradas o deportadas para sostener familias trasnacionales atravesadas por el régimen global de fronteras descrito. También para sostenerse ellas mismas en los múltiples procesos exílicos que experimentan.

Finalmente, presentamos algunas conclusiones sobre por qué y para qué resulta central reflexionar, desde la sociología de las migraciones y el feminismo, sobre las identidades emergentes de las mujeres migrantes. Ponemos especial énfasis en los aprendizajes de la experiencia encarnada del feminismo antirracis$\mathrm{ta}^{5}$, develada por la historia vital de Ana Laura López, la cual aporta elementos importantes al campo de estudio de las identidades.

\footnotetext{
4 Esta noción la propone la filósofa tijuanense Sayak Valencia para pensar nuevas formas de ciudadanía no ancladas en relato, trampa digo yo, de la ciudadanía como dispositivo moderno liberal que otorga subjetividad jurídica al tiempo que pertenencia política a los individuos. Por ciudadanía, Valencia propone comprender que el trabajo de la reproducción, eso que Amaia Pérez llama la economía feminista manifiesta en el circuito de los cuidados, como una de las líneas de fuga más fecunda para desbordar el debate político, filosófico y estratégico de la gradación racializada de la ciudadanía en sociedades receptoras de migrantes (VARELA, 2015; GROSFOGUEL, 2012).

5 Por feminismo migrante nos referimos a prácticas de agenciamiento político, latente o manifiesto, por parte de mujeres que se asumen o autoidentifican a partir de la experiencia de ser migrantes, refugiadas o asiladas y, desde ese lugar de enunciación, performan prácticas políticas diversas que construyen vidas que se puedan habitar para ellas mismas y para sus comunidades, diaspóricas (en los territorios donde migraron) o transnacionales (en los territorios de los que salieron expulsadas pero con quienes mantienen un lazo económico (por enviar remesas) y sobre todo afectivo y de pertenencia (VARELA, 2020).
} 


\section{Las preguntas motor de este texto y la artesanía metodológica que lo sostiene}

En este texto, como ya apuntamos en el resumen del mismo, intentamos resolver a través de escrutar la experiencia de una de nosotras, resolver tres preguntas eje o disparadoras. Construimos esta etnografía en clave de autorepresentacional radical para explorar ¿cómo se autorrepresenta una mujer migrante, madre, atravesada por el gobierno global de fronteras? ¿Qué discursos, prácticas y dispositivos de gubernamentalidad migratoria, pero también de género y raciales, operan para heterorrepresentar las maternidades en familias transnacionales? Y, finalmente, ¿en qué sentido estas dos lógicas de representación performan nuevas formas de ejercer el trabajo de la maternidad y la crianza?.

Así pues, en este texto proponemos una aproximación teórica sobre la subjetividad política que se ejerce a partir del ser madre migrante: atravesar sin permiso las fronteras de estados nación para conseguir "una vida que se pueda vivir" y, después de años o décadas de radicar ahí, convertirse en madre deportada, separada de sus hijos e hijas; construir estrategias afectivas y políticas para gestionar lo que en el estudio de las migraciones se llama "familias transnacionales", para hacer referencia a unidades familiares de estatus legal mixto, cuyos miembros viven en EEUU y México. Una subjetividad política que proponemos comprender como una más de las formas emergentes de feminismo migrante (VARELA, 2020).

El trabajo de investigación que reseñamos en este artículo se construyó colaborativamente con base en herramientas de corte cualitativo. Específicamente, la deriva investigativa, la observación/escucha entre la etnógrafa y la organizadora comunitaria, protagonista de este relato. Se realizó en varios encuentros políticos, dialógicos y afectivos que resultaron en entrevistas de corte semiestructurado, usando la técnica de relato de vida, una herramienta de la investigación acción participante de la familia de la historia oral (VARELA, 2009) durante la primavera y hasta el otoño de $2018 .^{6}$

Un relato de vida es una modalidad de entrevista en profundidad, que tiene por objeto conocer un proceso social a través de la experiencia vital del entrevistado. El relato biográfico ofrece una compleja diversidad de elementos para reconstruir procesos sociales (BERTAUX, 2005; FERRAROTTI, 2007).

\footnotetext{
6 Este artículo también es una línea de fuga, los últimos ecos del ejercicio de caminar preguntando, literalmente, con las madres centroamericanas que buscan a sus hijos e hijas, a sus parejas o padres y madres, en las rutas de transmigración mexicanas, de este que ellas llaman país retén o frontera vertical (VARELA, 2013b).
} 
Es un esfuerzo de coproducción de voces migrantes para pensar las maternidades de mujeres que se fugaron de la pobreza y la violencia. Que pagaron cuotas de sufrimiento individual y colectivo por desafiar las fronteras de instituciones que las "extranjerizan permanentemente" (BENHABIB, 2005). Y que, años después, otra vez la frontera las atravesó (ANZALDÚA, 2016) cuando fueron deportadas a México.

Proponemos interpretar estas voces migrantes como subjetividades políticas y culturales, y analizarlas desde el estudio interdisciplinar sobre las identidades, campo de estudio que Marcela Lagarde define como:

Para los fines analíticos de este trabajo, concibo a la identidad como la definición de una forma-de-ser y una forma-de-estar en el mundo que se adquiere a lo largo del proceso constitutivo del sujeto. Con base en lo anterior, se puede pasar a un nivel medio de abstracción en el que hay una pluralidad de sujetos que se constituyen a través de un conjunto de demarcaciones, reales y simbólicas, basadas en el reconocimiento de la semejanza, de la diferencia y de la especificidad, las cuales dan lugar a categorías sociales específicas resultado de la apropiación particular de los elementos identitarios definidos por el género (LAGARDE, 1996, p.44 apud LOAEZA REYES; CASTAÑEDA, 2014, p.31).

Este archipiélago de teorías y metodologías derivadas de las políticas de identidad ha sido de crucial importancia para quienes hacemos una socioantropología sobre las migraciones contemporáneas porque, gracias al giro semántico del posestructuralismo del siglo pasado (APPADURAI, 2001), por los giros semánticos epistémicos y simultáneos del feminismo (LOAEZA REYES; CASTAÑEDA, 2014), la poscolonialidad (SUÁREZ-NAVAZ; HERNÁNDEZ, 2008) y lo corporal (GÓMEZ PEÑA, 2005; FUSCO, 1994) con que hoy leemos los procesos sociales, pensamos en la heterorrepresentación jurídica, cultural, política y subjetiva de los que la filósofa Seyla Benhabib (2005) llama los Otros perpetuos, al ser los migrantes los perpetuamente extranjerizados por las democracias liberales.

Las teorías y métodos para comprender las identidades también nos permiten entender que la demanda de organizaciones de migrantes en todo el mundo sobre nada sobre nosotros sin nosotros. Puede contaminar (en un sentido positivo) las estrategias metodológicas y los abordajes teóricos que desde la socioantropología interpretan las migraciones contemporáneas. Porque la experiencia encarnada, de los cuerpos y sus narrativas, nos desafía a pensar las identidades 
colectivas con y desde los migrantes de la mano de la antropología cultural, que se pregunta por las identidades sociales (GIMÉNEZ, 1997).

Para nosotras, las voces de los propios migrantes deben ser consideradas no "relatos etnográficos", sino epistemologías producidas desde la experiencia de habitar cuerpos racializados y como discursos con "voluntad de verdad" (FOUCAULT, 2005), en donde la experiencia exílica, además de dolor, produce agencia, rupturas de genealogías de violencias, nuevas subjetividades, "conciencia de si” de sujetos permanentemente victimizados (VARELA, 2020), que además de dolientes son productores de sentidos. O, como recientemente dijo el antropólogo Arjun Appadurai:

Pero el archivo del migrante opera bajo otra limitación, ya que tiene que relacionarse con la presencia de una o más narraciones de la memoria pública en el nuevo hogar del migrante, donde éste es visto con frecuencia como una persona con una sola historia que contar: la historia de la pérdida y la necesidad abyectas. En su nueva sociedad, el migrante tiene que hacer frente a la minoría del archivo de migrantes, al bochorno de sus referencias remotas y a la pobreza de sus reivindicaciones sobre los "lugares de memoria” oficiales en el nuevo sitio. Así pues, el archivo electrónico se convierte en un espacio doblemente valioso para los migrantes, ya que en este espacio se puede compensar parte de la indignidad de ser menor o despreciable en la nueva sociedad, y se puede proteger la vulnerabilidad de la narrativa de los migrantes en la relativa seguridad del ciberespacio. (APPADURAI, 2019, p.5, traducción propia).

Recuperamos además la apuesta central de los trabajos sociocientíficos, que parten de reconocer la experiencia de los actores como productores de verdad, porque, de la mano con quienes hacen estudios del performance (FUSCO, 1994), reconocemos los cuerpos como territorios de inscripción de normas y roles, pero también como lugar productor de resistencias y resignificaciones.

El cuerpo, desde nuestro punto de vista, es un campo semántico, una frontera con el otro radical y las narrativas sobre nuestro habitar la vida, bitácoras de la historia contemporánea que, puestas en diálogo con el contexto y las estructuras, significa una especie de instantánea socioanalítica para comprender el presente. Para nosotras, la autoetnografía es un dispositivo que construye la memoria de nuestras luchas, ausencias y dolores. Es una especie de espejo para que quienes la lean se reconozcan en ellas. 
Nos hace eco lo que Patricia Castańeda propone cuando se pregunta sobre para qué sirve producir un saber situado en torno a las identidades sociales:

[...] lo que les permite "asir" procesos subjetivos como los valores, creencias, cogniciones y los procesos de memoria, analizándolos simultáneamente como procesos individuales y colectivos socialmente situados, que se interrelacionan y permiten explicar el sentido de las acciones de los sujetos que se analizan. De esta manera, explican la forma como dichos factores están involucrados en la producción, reproducción y contestación del poder, pero también en las luchas por establecer el sentido en la vida cotidiana. (...) la experiencia (es) como uno de esos conceptos clave que permite acceder a la articulación entre identidad y vivencia, reflexión y cotidianidad (LOAEZA REYES; CASTAÑEDA, 2014, p.11).

Partir de la memoria autobiográfica de las mujeres, madres, deportadas, nos guía por las nuevas formas de subjetividad política, de hacer política. Como Claude Dubar (LOAEZA REYES; CASTAÑEDA, 2014), pensamos que la narratividad es un proceso colectivo donde se concretan saberes situados. En nuestro caso, la experiencia de ser madre, ser migrante.

La autoetnografía que presentamos a continuación obedece a intereses teóricos y políticos, apuesta por vincular las maternidades de los pueblos en movimiento con la justicia transicional: que se reconozca la violencia de las políticas de extranjería que separan a las familias migrantes, para que se haga justicia y se repare a las víctimas. Pero, sobre todo, para garantizar la no repetición del confinamiento en jaulas a temperaturas bajo cero de bebés, niños y nińas migrantes.

Es también una apuesta política para que las luchas feministas que se preguntan por otras formas de maternar y habitar la crianza, consideren las maternidades de las mujeres migrantes y a las familias transnacionales como otro modelo más.

Como ya dijimos, este artículo parte de la pregunta motor sobre el derecho a la autorepresentación radical?

Como propone Loaeza Reyes y Castañeda (2014), nos parece que el estudio de las identidades nos permite construir una multiposicionalidad crítica frente a los entramados sociales contemporáneos.

Así mismo, para realizar este ejercicio, partimos de tres hipótesis fundamentales a demostrar argumentativamente con la memoria migrante que curamos: 
1. Las migraciones femeninas representan un elemento constitutivo de la historia de la especie humana. Lo novedoso es la mirada feminista a las migraciones, eso que en los estudios migratorios se ha llamado "feminización de las migraciones" (HERRERA, 2016). Desde nuestra perspectiva, la presencia paritaria de mujeres en los stocks migratorios ${ }^{7}$ de los nortes del mundo (las mujeres somos la mitad de los migrantes en el mundo) demuestran que la práctica de fugarse de la muerte en vida, o del lugar de nacimiento donde Wallmart y otras empresas transnacionales han conseguido establecer jornadas laborales de hasta 60 horas semanales de manera legal y pagar por ello la décima parte de lo que paga a estas mismas trabajadoras con cuerpos racializados en los nortes del mundo (VARELA, 2017), es ya en sí misma una práctica de desobediencia manifiesta al régimen global de fronteras.

2. Las estrategias de las mujeres migrantes para maternar transnacionalmente reconfiguran la economía de los cuidados (PÉREZ OROZCO, 2014). Al mismo tiempo, inventan otras formas de ser familia en las que la subjetividad femenina no se ve confinada, como el imaginario patriarcal la ha consagrado, al trabajo de los cuidados y la crianza. Migrando, las mujeres preservan su vida, garantizan la sustentabilidad de sus familias nucleares $y$, muchas veces, las ampliadas y las tramas comunitarias.

3. Por el régimen de deportabilidad, maternar transnacionalmente significa para millones de madres (ABREGO, 2014) ser encarceladas por meses en Estados Unidos para, después, ser deportadas a México.

Con estas preguntas, estas hipótesis de trabajo y el relato de vida de una mujer migrante deportada que ejerce la maternidad transnacional, curamos su historia de vida. Pues, como recomendó Sandra Harding, cuando dijo que hay que "Empezar por la vida de las mujeres", consideramos, con Castañeda, que "A través de la experiencia es posible indagar el carácter de la relación indivi-

\footnotetext{
7 Esta categoría propia de la sociodemografía hace referencia a los registros demográficos que las sociedades de instalación de los y las migrantes poseen luego de cruzar numeralias sobre participación tributaria y laboral, uso de los servicios que el estado de bienestar provee con los impuestos devengados a migrantes (que pagan con o sin tener los papeles en regla los no nacionales de dichas sociedades), al tiempo que la explotación de registros de carácter censal. Es decir, mientras que las sociedades expulsoras cuentan las migraciones a través sobre todo de las remesas recibidas y los territorios transfronterizos cuentan a los migrantes en términos de "eventos de cruce", las cifras que arrojan los stocks migratorios son siempre las más confiables para comprender el volumen real, y sus características sociodemográficas de las diásporas de migrantes en los nortes del mundo.
} 
duo/sociedad en la cual se gestan procesos de adopción, aplicación, innovación, creación y recreación de los contenidos identitarios, concebidos como históricos, contingentes y revisables." (HARDING, 1998 apud LOAEZA REYES; CASTAÑEDA, 2014, p.37).

\section{"Cada persona tiene derecho a estar dónde su corazón está".}

\section{La experiencia de maternar transnacionalmente de Ana Laura López, fundadora de Deportados Unidos en la Lucha}

Ana Laura López es una mujer mexicana de 44 años y madre transnacional. Fue migrante "sin papeles" en Estados Unidos, donde luego se convirtió en activista sindical y por los derechos de los migrantes. Desde ese país fue proveedora de remesas antes de ser deportada. Ahora, afincada en la Ciudad de México, sigue siendo cabeza de una familia transnacional y forma parte del entramado asociativo de deportados en México. ${ }^{8}$

Ésta es la historia de una mujer a la que Estados Unidos deportó sin su hijo norteamericano, ilegalizada por las leyes que extranjerizan a cuerpos racializados. De ese lado quedaron su trabajo como organizadora comunitaria y sus 16 años de habitar Chicago. Lo único que pudo traer consigo fueron recuerdos de gozo, de dolor y de rabias, aprendizajes y ańos de distancia con sus otros 4 hijos residentes en México, motor de su migración.

Es la historia de una mujer única. Al mismo tiempo, es un ejemplo de los millones de mujeres que, expulsadas de sus comunidades por el neoliberalismo, tuvieron que aventurarse a la fuga migratoria para preservar su vida, pero, sobre todo, la de sus hijos. Mujeres que después de reinventarse en el exilio, fueron deportadas por la máquina de deportabilidad norteamericana.

La deportación de mexicanos desde Estados Unidos es un elemento constitutivo del sistema migratorio norteamericano desde los tiempos del programa Bracero (DE GÉNOVA; PEUTZ, 2010), pero hoy representa un desafió por su volumen y características. Estamos ante un dispositivo de gobierno cuyo objeto es romper los vínculos más elementales de las comunidades binacionales y transnacionales a través de señalar, acechar y finalmente deportar a proveedoras y proveedores de unidades familiares de estatutos legal mixto (legales e ilegaliza-

\footnotetext{
8 Una versión de este testimonio ya fue publicada como ejercicio de autobiografía en la revista Narrativas del Inah en julio de 2020. Lo presentamos en este artículo después de una cuidadosa curaduría del mismo y enmarcado en las preguntas de investigación y perspectivas teóricas propuestas.
} 
das). Estas deportaciones fragmentan las posibilidades de sobrevivencia básicas y debilita los lazos afectivos, al separar familias hasta desgarrarlas.

En 2016, bajo el régimen del presidente electo de Estados Unidos, Barack Obama, Ana Laura López, la protagonista de este trabajo, llegó a México después de ser deportada. Su caso es uno de los cerca de 4 millones de personas, entre mujeres y hombres de diferentes edades, "devueltos" a México y América Central después de permanecer largos periodos en Estados Unidos. Se estima que la mayor parte de esta población son hombres, en su mayoría padres de familia. Pero desde la administración Obama y ahora la de Donald Trump, de 2011 a la fecha, el número de mujeres deportadas incrementó, de acuerdo con la Secretaría de Gobernación. Para el año 2018 se contabilizaron 155,833 de mujeres, entre ellas 14,791 menores de edad, expulsadas de Estados Unidos (UPMRIP, 2010, 2019). ${ }^{9}$

Este panorama coincide con dos fenómenos recientes en el mundo de la migración, el de la feminización de los flujos migratorios desde la neoliberalización de América Latina (1990’s) y la puesta en práctica de andamiajes feministas para leer las migraciones. En este relato de vida veremos las dos dimensiones mencionadas. Es un relato en clave feminista, que explica la vida de las mujeres migrantes que son madres transnacionales y que conforman, a su vez, familias transnacionales con los roles de género reconfigurándose constantemente.

Ana Laura nos muestra la amistad como práctica política, que antecede a formas tradicionales, como el sindicalismo. Y veremos cómo ese sindicalismo la sumerge de lleno en las luchas migrantes con las que se reinventa como mexicana, como trabajadora, como activista. Transforma su "ser mujer misma" y cuestiona de raíz la autoidentificación con formas de habitar la vida.

Es una reflexión en primera persona sobre la experiencia de la deportación, la vergüenza de ser expulsada, pero también la dignidad que provoca "salir de las sombras". Es un ejercicio de autorreconocimiento sobre las formas de gestionar la culpa. Sobre la soledad de una mujer que se reinventó y volvió a un territorio que permanece "atrapado" en relaciones patriarcales.

Es una narración atravesada por la ira, la tristeza, la melancolía, pero también por la dignidad y la astucia para recuperarse del duelo migratorio, organizándose. Es un relato que nos interpela a comprender formas de participación

\footnotetext{
9 Según el informe de la Unidad de Política Migratoria, Registro, Identidad de Personas de 2019, entre los deportados estos ocho años, el $83.3 \%$ de los hombres y el $33.5 \%$ de las mujeres formaban parte de la Población Económicamente Activa (PEA), cerca de la mitad de estos "retornados" tienen entre 30 y 45 años. Es decir, Ana Laura López es un ejemplo de uno de cada diez deportados y deportadas en México.
} 
política que parten de "poner el cuerpo", traducir lo aprendido para las luchas entre los deportados que no son dreamers en el México contemporáneo.

Para empezar a compartir la historia de Ana Laura nos parece importante acotar que los motivos que provocaron el éxodo de esta y muchas otras mujeres puede resumirse en tres: violencia de mercado (la miseria que acarrea el neoliberalismo en sus vidas), la violencia de Estado (por la impunidad con la que opera la violencia económica y social contra las mujeres, pero también por la virtual experiencia de intemperie institucional a la que las madres solteras o jefas de familia monoparentales se enfrentan de cara a las instituciones hiperadelgazadas del estado de bienestar) (VARELA, 2017).

Ana Laura López es originaria de la Ciudad de México. Su infancia estuvo marcada por el abandono de un padre alcohólico y una madre proveedora, pero "sometida" a su cónyuge. A los 16 años contrajo matrimonio con un hombre también alcohólico. A los pocos meses de nacido su cuarto hijo, la pareja de Ana Laura emigró a los Estados Unidos. Volvió a saber de él cuando éste reclamó la tutoría de sus hijos, para entonces la familia de Ana Laura se había convertido ya en lo que en los estudios migratorios llamamos familias transnacionales. Porque, para sostener a sus hijos, Ana Laura, emigró primero de la capital a una ranchería de Jalisco, donde contaba con lazos familiares que resguardarían a sus hijos cuando ella decidió fugarse de trabajos mal pagados, largas jornadas laborales y ver a sus hijos pasar hambre. Y años más tarde, Ana Laura viajó sola a Estados Unidos, pagando coyotes. "Mis hijos estaban muy chiquitos, Yosi tenía como 8 años; Jesús, 6; Ximena tenía como 2 años y medio y July, como año y medio." (Entrevista con Ana Laura López, Ciudad de México, 2018)

Antes de reunirse con su segundo compañero sentimental en Chicago, pasó meses de confinamiento en un centro de detención en EEUU. Luego de varios intentos, desafiando las fronteras que dividen a México de Estados Unidos, logró cruzar.

\section{Ya del otro lado del muro}

Meses después de su llegada, comenzó a trabajar con una tarjeta de residencia falsificada con un número de seguro social "prestado".

"Empezó una nueva vida para mí. Llegué muy contenta y cuando vi Chicago, me enamoré y sigo enamorada de Chicago, ahí viví los mejores años de mi vida. Empecé a trabajar en una tienda de segunda, que fue mi trabajo por casi 10 ańos, la Unique. Aunque en un principio mi idea era trabajar de uno a dos años y volver”. 
Ana Laura mantuvo comunicación con sus hijos y su madre en México a través de cartas y llamadas telefónicas. Semanalmente les enviaba remesas. Por años, intentó un acuerdo con su exmarido para que firmara el permiso parallevarse a sus hijos a EEUU, pero su exmarido, que había retornado voluntariamente a la Ciudad de México desde EEUU, nunca cumplió su palabra y mantuvo siempre con él a los hijos de Ana Laura. .

Ana Laura tuvo otros dos hijos. Entonces, proveía dinero al nodo en México y cuidados y sostén al nodo en EEUU. Miguel, su segunda pareja, inseguro por la diferencia de edad, utilizó el estatus migratorio de Ana Laura como chantaje para mantenerla "bajo control". Nunca accedió a firmar un contrato matrimonial que regularizaría su situación migratoria.

A partir de aquí Ana Laura relata en primera persona su experiencia:

En el trabajo todas éramos mujeres, migrantes y la mayoría indocumentadas. Creamos un núcleo muy fuerte, aún seguimos siendo muy amigas. Éramos 'Las únicas', así se llamaba nuestro grupo, 'Las únicas'. Somos como familia realmente.

Para mí, la vida perfecta era el estilo de allá: ni rica ni pobre, viviendo dignamente, o sea, con tiempo para mis hijos. Así como las películas gringas que muestran lo que es el sueño americano, así era mi vida, yo estaba muy feliz. Siempre viví en un espacio aparte, Miguel rentó un lugar y siempre viví aparte. Nacieron mis hijos y traté de darles la mejor vida que pude.

El problema empezó cuando nos avisaron en la tienda que iban a vender las tiendas. Yo hacía de todo, era cajera, ponía precio, estaba a cargo del área de miscelánea. Si no hubiera hecho nada, yo fuera supervisora.

Cuando vendieron las tiendas todo cambió. Las compró una compañía más grande de tiendas de segunda que se llama Seiver, que son bien explotadores y despidieron a mucha gente. Se empezaba a notar que iban a implementar el E-Verify, una verificación electrónica con una base de datos que comparte migración y la oficina del seguro social para checar tu número de green card y tu número de seguro social.

Para protegernos, empecé a estudiar para sacar el GD, que es el equivalente de sacar la prepa abierta y empecé a estudiar inglés. Fue un año súper pesado, mis hijos ya estaban grandecitos. De hecho, tengo fotos de mi graduación con ellos.

Entre mis compañeras, yo era la que más hablaba inglés y la que más sabía usar computadora. Entonces, investigué en Google y me apareció la organización Arise Chicago ${ }^{10}$; les llamé y me avisaron de un taller de derechos laborales. Lo

\footnotetext{
${ }^{10}$ Worker Center, o centro de trabajadores, un modelo de organización alternativo a los sindicatos que surge para empoderar a trabajadores migrantes sin papeles y, por lo tanto, poco adeptos al sindicalismo tradicional. Es un
} 
tomé y dije: “¡Wow! Tenemos derechos laborales a pesar de estar indocumentadas."

\section{Aprendiendo a ser organizadora sindical}

Les conté a mis amigas, éramos 15; mexicanas, ecuatorianas y una salvadoreña. Organizamos una reunión y les dieron el taller a todas, así surgió la idea de sindicalizarnos. Tuvimos citas con sindicatos para decidir a cuál afiliarnos e inició la campaña. Realizamos acciones, pero la nueva jefa nos amenazó con que ya nadie podía hablar español: 'puro inglés y nadie les va a traducir'. Algunas entendían, otras no, así que les tradujimos. Nos quedamos viendo y dijimos: "vámonos".

Por el taller de derechos laborales sabíamos que si nos íbamos lo tomarían como que dejamos el trabajo. Entonces, hicimos pancartas y dimos vueltas por la banqueta. Se armó un merequetengue porque vinieron los de Araise Chicago. Hablamos con la empresa y llegamos a un acuerdo. Ahí surgió la campaña de sindicalización. Pero la empresa armó una contracampaña: le lavaron el cerebro a mis compañeros. Éramos 15 que estábamos muy sólidas, pero habían empleados de piso, la mayoría, afroamericanos. En total, éramos 45 de toda la tienda.

Hasta nos secuestraban, nos metían dos horas en un cuarto para ver películas de lo malo que eran los sindicatos, cómo dañan y te quitan tu dinero. Eso hizo que, sobre todos los afroamericanos, no confiaran. Perdimos la votación, por una pequeña diferencia, pero la perdimos. Fue un 12 de diciembre, por cierto, de 2012.

Y ni modo, una semana más y nos despidieron. Levantamos una demanda ante la Junta Nacional de Relaciones Laborales y la ganamos. Aunque fue lo mismo, lo que ganamos fue que nos regresaran el trabajo, pero al volver ellos tenían todo el derecho de pedirnos los papeles y revisarlos. Fue un triunfo simbólico.

Pero fue muy bonito porque todas llegamos hasta el final. Aunque fue una derrota, todas ganamos ese valor de pararte de frente y decir: 'Ya no más. Ya no me vas a estar humillando, ni me vas a estar insultando. Ya no vas a estar abusando de mí". Eso es lo que no he visto aquí en la Ciudad de México. Esa que, ganes o pierdas, te des cuenta que aprendiste. La lucha por tu dignidad siempre vale la pena, aunque el resultado se vea contraproducente. Eso lo aprendimos todas y es la razón por la que seguimos unidas hasta ahorita.

modelo llamado "sindicalismo social" que organiza a los trabajadores dentro y fuera de sus centros de trabajo tejiendo redes de solidaridad comunitaria. También lo capacita para la autodefensa migrante. Para este Worker Center en particular véase: https://www.arisechicago.org/history. Acceso en: 21 set. 2021. 
Solo yo estoy deportada, y otra compañera se regresó por su cuenta porque sí se puso bastante complicado. Ella es Aurorita, se regresó como dos años antes que yo. En la campaña de sindicalización había que firmar la lista de quiénes íbamos a las reuniones, porque como era considerada una acción concertada, está protegida por la ley. Si ellos nos hubieran acusado con la migra, eso nos valía para una visa.

Ahí me di cuenta de que Aurorita y Tachita no sabían leer y escribir y ya llevaban 25 años trabajando para Unique, son las que llevaban más tiempo. Revisamos los cheques y vimos que había mucho robo en el salario. Como no sabían leer ni escribir, no sabían lo que les pagaban. Yo les di clases de alfabetización, por lo menos les ayudé escribir su nombre y cositas así.

Cuando salimos, di clases de alfabetización en el Centro Monseñor Romero $^{11}$. Es grande ese problema, hay mucha gente analfabeta en Estados Unidos, mucha.

Después de que me corrieron, pedí trabajo en una panadería grande. Se dieron cuenta que los papeles eran chuecos y me dijeron que no. Entonces, entré a una agencia temporal de colocaciones, esos son los peores explotadores laborales que puede existir. Hay gente que tiene 15 ańos trabajando en un mismo lugar en calidad de temporal, lo que significa que no tienes derecho de nada. Ya para ese tiempo yo sabía de todo esto de los derechos laborales. Fue así como dije que ya no quería trabajar en nada de eso, quería algo diferente para mi vida.

Tomé una decisión radical: dejé de trabajar año y medio y viví de mis ahorros, que ahora me hacen falta. Pero lo que aprendí en ese año y medio ha sido mi herramienta para sobrevivir aquí en la Ciudad de México.

Estudié computación, me involucré con Mujeres Latinas en Acción ${ }^{12}$ y tomé un curso de liderazgo. También el de "Empresarias a futuro", gracias a eso nació Deportados Brand ${ }^{13}$, te dan educación financiera, de marcas, y de cómo

\footnotetext{
${ }^{11}$ El Centro Romero, afincado en Chicago desde la década de 1980, cuando llegaron los primeros salvadoreños exiliados de la guerra contrainsurgente en su país, fue fundado con el propósito de generar, a través de diferentes programas de formación política, jurídica y de alfabetización, la autosuficiencia de las comunidades refugiadas y migrantes en Estados Unidos. Lleva el nombre del hoy canonizado Monseñor Arnulfo Romero, defensor de los derechos humanos en El Salvador, asesinado en 1980, mientras celebraba una misa. Véase: http://centroromero. org. Acceso en: 21 set. 2021.

12 Organización sin fines de lucro, cuya misión es el empoderamiento de las mujeres latinas en EEUU, afincada en Chicago, véase: http://www.mujereslatinasenaccion.org/. Acceso en: 21 set. 2021.

13 Deportados Brand es una microempresa que crearon algunos de los activistas de Deportados Unidos en la Lucha, es un esfuerzo de autoempleo basado en los saberes de diseño gráfico, serigrafía e impresión, además de las habilidades en mercadeo que los miembros de este colectivo traían en las mochilas vitales antes de ser deportados y que, como diversas experiencias, pusieron en una apuesta colectiva para autosustentarse. Véase https://www. facebook.com/DBSerigrafia/. Acceso en: 21 set. 2021.
} 
de la nada puedes crear un negocio, empezando a vender dulces. Fue lo que yo apliqué aquí.

Estaba más con mis niños, ya tenían como 12 y algo. Ese año me la pasé aprendiendo de Mujeres Latinas en Acción, que es muy reconocida en Estados Unidos, trabaja con sobrevivientes de violencia doméstica. Ahí tomé consejería, porque, a la par, yo tenía muchos problemas. Yo quería ir a México, quería un mejor trabajo y eso creó conflictos con mi pareja, porque él no quería.

En Estados Unidos estás muy protegida como mujer. Pero a la vez no, porque viví con él 16 años, pero eso no me da derecho a nada. Si me hubiera casado con él podría aplicar a otro tipo de visa. Eso me trajo muchos problemas emocionales, lo de mi trabajo, ir al otro y que me rechazaran por no tener documentos, una se siente avergonzada. Le decía: ‘¿por qué eres tan malo, Miguel?'. Si se hubiera casado conmigo nada de esto hubiera pasado, hubiera arreglado mis papeles.

Por eso fui al grupo de Mujeres Latinas en Acción, por los grupos de apoyo. Aprendí que la violencia doméstica no es nada más física y es muy común. Había muchas mujeres como yo, que sus parejas eran ciudadanos y a través de esto ejercían control sobre nosotras.

Luego, empecé a ser voluntaria en Arise Chicago y en Latino Union of Chicago $^{14}$. Latino Union trabaja más con jornaleros, personas que trabajan por día y que se ponían en las gasolineras y en los Home Depot, ahí va gente y las contrata. Pero sufren abusos y Latino Union los asesora para organizarse, estar protegidos y hacer valer sus derechos laborales. Con ellos aprendí mucho de ese tipo de organización, y todo eso es lo que he aplicado al colectivo y a Deportados Brand.

A Miguel, el padre de mis hijos, le valía. De alguna manera, él tenía el control. Vivíamos en una zona muy bonita de Chicago, al norte, porque en el sur hay más violencia, desgraciadamente. Siempre vivimos en una zona de anglosajones. Él sabía que, por mis hijos, yo no iba a cambiar esa vida. Si lo dejaba, me tenía que ir al sur y poner en riesgo a mis hijos. Él sabía que tenía el control.

Miguel maneja un camión y tiene un tráiler, siempre ha ganado decorosamente. No es malo, su único problema fue el machismo, su inseguridad y el miedo a la soledad.

\footnotetext{
14 Organización de mujeres migrantes que surgió en 2000 buscando mejorar las condiciones de contratación en agencias temporales y que hoy se dedica a la educación en derechos sindicales y derechos humanos de migrantes con y sin papeles. Véase: https://www.latinounion.org/. Acceso en: 21 set. 2021.
} 
A Arise Chicago le llamó la atención el interés que yo tenía, entonces me invitaron a más cursos, me pagaron capacitaciones en la Universidad de Illinois sobre liderazgo y organización comunitaria. Todo estaba enfocado a mujeres, para mí era como un sueño estar viviendo todo eso.

Osha, que es la Agencia de Seguridad y Salud ocupacional, me ofreció una beca y me convertí en train de trainers, como entrenadora con especialidad en ergonomics, en ergonomía, que es que el sitio de trabajo sea seguro, que se adecue al trabajador y no el trabajador al sitio de trabajo. Aprendí de las leyes laborales de salud y de seguridad, yo estaba muy contenta.

Fueron como dos ańos de aprendizaje, me fueron delegando más responsabilidades, pero todo voluntario. Hasta que me contrataron como coordinadora de educación de Araise Chicago.

\section{Los intensos años como Community Organizer}

Era la encargada de los cursos de derechos laborales. Me pagaban a 21.75 dólares la hora, en Unique ganaba 8.50 la hora, el salario mínimo, pues. Me pagaban incluso 'las millas', la gasolina desde que sales de tu casa. Daba talleres de derecho laboral, de derecho de salud y de seguridad social. Estaba feliz de la vida.

Todo estaba perfecto, pero desgraciadamente tuve un problema fuerte con Miguel, donde hubo unos aventones por parte de los dos. Peleamos bastante fuerte y llegó la policía, se lo llevaron detenido a él y ahí como que cambió mucho, porque yo tenía una orden de restricción. Aunque podíamos convivir en la misma casa, no se podía meter en mi vida.

En ese tiempo, como aquí, me invitaban a las reuniones del consulado. Me iba con mis hijos o sola, y es ahí donde Miguel me empezó a cuestionar el porqué. Ese día tuvimos una discusión. Pero como no fue una agresión fuerte no podía calificar como una visa $\mathrm{U}^{15}$.

Eso me hizo cuestionarme y dije: 'Ya no más. Quiero ser independiente'. Le propuse que se fuera, pero que me ayudara con la renta del departamento,

\footnotetext{
${ }^{15}$ El estatus No Inmigrante U (Visa U) es para víctimas de abuso físico o mental. El Congreso creó esta visa mediante la aprobación de la Ley de Protección a Víctimas de la Trata de Personas y Violencia (incluyendo la Ley de Protección de Mujeres Inmigrantes Abusadas) en octubre de 2000. La legislación está dirigida a fortalecer la capacidad de las agencias del orden público para investigar y procesar judicialmente los casos de violencia doméstica, abuso sexual, tráfico de extranjeros y otros crímenes. Protege las víctimas que están dispuestas a ayudar a las autoridades en la investigación y prosecución de la actividad criminal (Información publicada por el gobierno de Estados Unidos, en línea, https://www.uscis.gov/es/programas-humanitarios/victimas-de-la-trata-de-personasy-de-otros-crimenes/victimas-de-actos-criminales-estatus-u-de-no-inmigrante. Acceso en: 21 set. 2021.
} 
que era bastante. Era complicado porque yo tenía que mandar dinero a México. Le propuse separarnos, saqué la orden de restricción y le dije: 'Tú a mi vida no te puedes meter y no puedes rebasar mi espacio personal, ni nada por el estilo'.

Me involucré con otra organización que creó una líder que salió de Mujeres Latinas en Acción, se llama Un nuevo despertar ${ }^{16}$. La fundadora me daba otro poquito de dinero por apoyarla. Estaba muy contenta y hablé con la gente de Arise Chicago para que me patrocinaran' para obtener mis papeles. El proceso para regularizarme era riesgoso porque tenía que salir de Estados Unidos. No nos asesoramos bien y no nos imaginamos lo que iba a pasar.

Ángel, mi primer hijo con Miguel, es mexicano y los abogados me dijeron que tenía que salir y hacer un trámite para legalizarse. Nunca se hizo porque nos daba miedo, ahora que estoy en Ciudad de México sé que califica como ciudadanía derivada, por ser hijo de un ciudadano norteamericano ${ }^{17}$. No te imaginas, enterarnos de eso hasta estos ańos, apenas hace unos meses encontré a la persona que lo llevará a cabo, gracias a un centro comunitario en Chicago.

Tomé la decisión de venir a México en junio de 2016. Sabía que era riesgoso, pero dije: 'No tengo récord criminal, no creo que haya ningún problema. Sólo es pagar el trámite del perdón y lo que se tenga que pagar'. Compré el boleto para viajar el 30 de septiembre. Quería darles una sorpresa a mis hijos. Los primeros días, había planeado, iría a un hotel y después les daría la sorpresa de que andaba por acá, serían solo unos meses.

\section{La deportación}

Mis abogados de Arise Chicago y yo calculamos que era un trámite de unos siete u ocho meses, máximo un año. Lo que cambió todo fue cuando documenté mi maleta. Todo iba bien, entré casi al último porque me estaba despidiendo de mis hijos, pasé Seguridad Nacional y ya para llegar al avión, ya para abordar, vi a dos agentes de ICE en la puerta del avión.

Me revisaron los papeles y me requisaron el pasaporte. Me llevaron a sus oficinas en el aeropuerto y me revisaron las huellas, la computadora dejó ver las dos 'agarradas' que tuve cuando ingresé a Estados Unidos. Pregunté: ‘¿Puedo

\footnotetext{
${ }^{16}$ Organización sin fines de lucro dedicada al acompañamiento de procesos contra la violencia doméstica en la comunidad latina. Acompañan desde jurídicamente hasta en aspectos emocionales y empoderamiento económico. Véase: http://www.unnuevodespertar.org/. Acceso en: 21 set. 2021.

${ }^{17}$ La ciudadanía derivada es un procedimiento de asignación de ciudadanía para hijos de naturalizados estadounidenses. Los requisitos para obtenerla se detallan en los sitios oficiales del gobierno estadounidense, uno de los hijos de Ana Laura la obtuvo, finalmente, en 2020. Véasehttps://www.uscis.gov/es/ciudadania/aprenda-sobreciudadania/ciudadania-y-naturalizacion. Acceso en: 5 out. 2021.
} 
hacer una llamada?'. No me contestaron. Fueron como 20 minutos, ya estaba espantada, lo que pasaba por mi mente era el centro de detención y pensaba: 'me van a hacer pasar otra vez por ese infierno'.

Fui torpe, porque son cosas que incluso había recomendado en mis talleres. Cuando me dijeron: 'Firma aquî', firmé. Estaba petrificada pensando que me iban a mandar a un centro de detención. Para mi sorpresa, me guiaron hasta el avión y todavía me dijeron: 'Que tengas buen viaje'. Me quedé con una inmensa vergüenza.

- Oiga, ¿y mi pasaporte?

— Lo tiene ella (la sobrecargo de la aerolínea Volaris).

Nunca he vuelto a usar esa aerolínea, actuaron como agentes de migración. Tomé mi asiento y sentí las miradas de la gente, ¡qué pena! Pasaron por mi mente muchas cosas, ya no hubo tiempo de hacer llamadas, ya no hubo nada que hacer. Ya volando, revisé los papeles y vi que era una deportación y que me habían dado una penalización de 20 años para no regresar. Fueron cuatro horas y media de pesadilla, yo quería bajarme. Fue una impotencia terrible.

Cuando llegamos a México me retuvieron como media hora. Me llevaron a Migración, confirmaron que soy mexicana y me dejaron salir. Traía como 200 dólares en la bolsa y mi tarjeta del banco, mi maleta estaba intacta. Nada más me instalé en un hotel le llamé a Miguel. Él sólo dijo: "Te dije que no te fueras". Después llamé a los de la organización.

Al día siguiente busqué a mis hijos, dentro de lo malo eso fue lo bueno, el reencuentro con ellos, 16 años de no verlos. Son desapegados a mí. El único que vive conmigo es Jesús, una de las chicas se juntó con su novio y la otra vive con su papá. Yoselin vive aparte con su esposo. Jesús ya no vivía con su papá, nunca se llevaron bien y se fue a vivir aparte y, ahora que regresé, se fue conmigo. Nos llevamos bien, pero no es como me llevo con mis otros hijos, con los chicos, que hay mucha confianza hasta para regañarlos. A ellos los he querido regañar por cosas y me han dicho 'Tú que te metes, si no estuviste con nosotros'.

La primera navidad me la pasé sola, porque ellos se reúnen con la familia de su papá. Tienen un enojo grande. Los quiero y saben que ahí estaré cuando lo necesiten, para escucharlos y económicamente también, les apoyo en lo que puedo. Pero han preferido mantenerse así, menos Jesús. Él trata de tener un acercamiento, las niñas no. Son los precios que hay que pagar. Hice lo que pude, les mandé lo que pude. A veces reclaman, Yoselin y Jesús son los que más recuerdan las cosas difíciles que pasamos cuando me fui y no las volvieron a pasar. 
Sí ha sido difícil, porque existe una culpa en mí por muchos años de estar allá. No me arrepiento de haberme ido, me arrepiento de haber tomado esa decisión, mejor me hubiera quedado allá como indocumentada.

Desgraciadamente, la única posibilidad es Miguel porque era una relación real. Migración checa todo eso, se da cuenta cuando es un matrimonio fraudulento. Él era la vía porque teníamos una historia, niños, hay fotos, contratos de rentas, hay mucha historia. La única forma sigue siendo él. Desde entonces y hasta ahora me ayuda, me manda dinero, pero con ese tema no. Quién sabe qué pase por su mente.

Yo creo que ahorita ya no me casaría con él. Todo esto me ha servido para ser independiente en muchos aspectos. Quiero regresar y estar con mis hijos, pero quiero intentar por otro lado. Tengo muchas contradicciones, si Miguel viniera y me dijera que nos casáramos y arregláramos los papeles, perdería lo que he logrado aquí: el darme cuenta que sí puedo sola, que puedo pagar la renta yo sola, que estoy sacando mi negocio con mis compańeros de Deportados Brand.

Hablé con los de la organización (Arise Chicago) y dijeron que no se puede hacer nada porque hay una deportación de por medio. Los abogados me ofrecen una sola vía: casarme con Miguel, que pague el "perdón” y, luego, hacer una petición de reagrupación familiar. $\mathrm{O}$ esperar a que mis hijos cumplan 21 y hagan un proceso de unificación familiar, para esto faltan 5 años. Son mis únicas dos opciones.

Pero para hacer reunificación familiar mis hijos tienen que tener un número de seguridad social que, a lo mejor sí, su papá se los da, quién sabe. Por eso me he enfocado en Deportados Brand porque quiero reunir elementos, soy una empresaria y así quiero manejarlo. Yo quiero reunir elementos para facilitar ese regreso, algún día sí se va a dar. Pero es triste que estos años ya nadie me los va a devolver, esos momentos con mis hijos.

El que ha venido a visitarme es Dani, Ángel no viene porque está en ese proceso de regularizar sus papeles. Dani dice que aquí no le gusta. Se preocupa, me pregunta cómo se saca una visa y más o menos le he explicado. De alguna manera ellos saben que son la vía para que yo pueda regresar a Estados Unidos.

Mi deseo es tener una libre movilidad. Poder ir y venir, porque aquí quiero a mucha gente, sobre todo a mis hijos, aunque no estén apegados a mí yo los quiero mucho. Además, está la gente que he conocido, como Deportados Brand. Allá sigue mi casa, el espacio donde viví tantos años, mis plantas, mis hijos, mis amigas. Me gustaría regresar a Chicago, siento más mi casa en Chicago que aquí. Quisiera tener esa libre movilidad, quiero luchar por eso. 


\section{Nuevamente, el proceso de instalación a la nueva realidad}

Aquí realmente no tengo muchos amigos ni familia. Los que me ayudaron cuando llegué fueron unos amigos de la secundaria, con quienes seguía en contacto por Facebook. Un amigo me prestó su departamento en Coyoacán, me ayudó con ese alojamiento y me hacía un mapa. Fueron mis amigos quienes me fueron guiando. Yo había estado fuera de esta ciudad 23 años, fueron 16 años en Chicago y ocho en Jalisco. Ernesto y Antonio me acompañaban a Arcos de Belén para conseguir una copia de mi acta de nacimiento, me guiaron para obtener mis documentos. Con base en ese apoyo surgió esa atención en Deportados Unidos en la Lucha.

Luego empecé a buscar dónde rentar, pero me pedían referencias, avales. De suerte, encontré un departamento, el dueño fue solidario y me lo alquiló sin fiador. Busqué trabajo y encontré en una escuela cerca de ahí, daba clases de inglés a niños de kínder.

Supe de SEDEREC (Secretaría de Desarrollo Rural y Equidad para las Comunidades) y del seguro de desempleo. En diciembre fui a una entrega del seguro en el museo Franz Mayer. Ahí estaba un político de Chicago, Chuy García, lo conocía por eventos de Arise Chicago, y me invitó a pasar el presidio. También estaba la secretaria del Trabajo, Amalia García, a ella la conocí en Chicago cuando hicimos la campańa de las trabajadoras domésticas. Cuando le tocó hablar mencionó que soy una persona que se dedicaba a los derechos de los trabajadores y que estuviera pasando por esto era injusto. Me dio la bienvenida.

Cuando terminó el evento uno de los muchachos me preguntó:

— ¿Tú viviste en Chicago?

— Sí, ¿̇tú también?

Resultó que todo el evento era para apoyar a retornados y deportados, yo no había puesto suficiente atención, éramos alrededor de 200. Nos fuimos juntando varios en una mesa, hablamos de lo difícil que era adaptarse, encontrar trabajo y dónde vivir, que tu familia aquí no te quiere y el estar separado de tu familia de allá. De la manera en que llegaron y qué medidas estaban recibiendo. Les propuse formar un grupo para visibilizar lo que nos pasaba. Fijamos una cita y nos reunimos diez días después afuera del Museo Franz Mayer, donde nos reunimos muchos meses más.

Yo ya estaba trabajando. Me pagaban 6,000 pesos al mes, era muy poquito. A la primera reunión que convocamos fueron dos personas, Salvador y Armando, nada más. Nos reuníamos para ayuda emocional, para platicar. Fue de mucho 
alivio contar nuestras historias, hablar de lo mismo y que por fin alguien nos entendiera, 'alguien se siente como yo'. Luego se fueron sumando más.

Empezamos ir al aeropuerto por todo lo que ellos me dijeron, que nadie los recibía, nadie les prestaba un teléfono y no se podían comunicar. Que los de ICE les rompían sus identificaciones. Fue así como fuimos a ayudar.

Investigué cuándo llegaban los vuelos. Con INM (Instituto Nacional de Migración) nunca conseguí información, fue a raíz de lo que ellos me platicaron, los martes a las 11 de la mañana. Fuimos a la terminal 2 del aeropuerto, y sí llegó el vuelo y, efectivamente, no había nadie, ni organizaciones. La Secretaría del Trabajo solo daban folletitos, no se acercaban para ver qué ocupas, qué necesitas, nada.

\section{Deportados Unidos en la lucha, organizarse en el destierro}

Deportados Unidos en la Lucha fue mucha idea mía, ellos querían ponerle otro nombre. Cómo eso de deportados, cuestionaban. Les dije: 'Miren, para ser claros, es lo que somos, deportados. Ésa es la palabra correcta que debemos usar'.

En Chicago no todos sabían que yo no tenía papeles. Cuando me deportaron, uno de los sentimientos que pasé fue de vergüenza. Pensaba: 'Y ahora, ¿cómo voy a decir que fui deportada?'. Yo no quería decir eso hasta que un día pensé: 'Tengo que decirlo, ni modo. Si no, cómo voy a encontrar ayuda'.

Soy la única mujer en DUL. Y de los aviones que llegan, son muy pocas las mujeres, la mayoría de los que deportan son hombres. Las pocas que conocí fue porque cruzaron por primera vez o por procesos similares al mío: arreglando sus papeles fueron deportadas, y no llegan en los vuelos que fletan, sino en diferentes.

Un día decidí dedicarme completamente a Deportados Unidos en la Lucha. Dejé mi trabajo y desde esa fecha, que fue como en enero del 2017, DUL se ha convertido en mi vida. Lo que hice primero fue darnos una identidad, mandé a hacer playeras para que nos identificaran.

No teníamos dinero ni trabajo, vendimos dulces, que fue lo que aprendí en Mujeres Latinas. Hicimos unos stikers y las playeras venían con el logotipo de la campaña: dos manos agarradas con esposas. Andábamos por Bellas Artes, nos íbamos al Zócalo y al Monumento a la Revolución. Hablábamos con la gente: "Mire, no somos criminales, somos padres separados de nuestros hijos".

Después creé la página de Facebook. Gracias a salir a la calle a platicar con la gente fue como ganamos seguidores en la página. La gente quiso com- 
prar las playeras, a la venta de dulces le había llamado Deportados Brand 100\% mexicanos.

Una vez mis amigos en Chicago me dijeron que (Miguel Ángel) Mancera (jefe de Gobierno de la Ciudad de México) estaría el Museo de Memoria y Tolerancia. Compramos cartulinas y escribimos: 'Somos deportados'. Me puse hasta en frente y fue cuando acabó su discurso, que me paró. '¡Somos deportados!', y le platiqué de nosotros.

Por instrucciones derivadas de este acto, juntaron a varias secretarías para ver qué pueden hacer con nosotros y en qué apoyarnos. Fue todo un logro, por fin miraron a esa población de arriba de 40 años, personas que no traen el inglés como herramienta laboral, personas que no traen un alto nivel educativo, regresan con el mismo nivel con el que se fueron: con la primaria y la secundaria. Y que lo principal que hicieron en Estados Unidos fue: jardinería, construcción, lavar carros o restaurante o trabajador en general.

Eso ha dificultado la reinserción. Para el gobierno es como si solo existiera el perfil de los Dreamers, piensan que son la mayoría, que tienen capacidades excelentes. Muchos las traemos, pero el gobierno ha dejado de lado a esta población. La labor del colectivo ha sido visibilizar esta población que también existe y necesita una atención diferente.

Ha sido difícil. Cuando conocí a la mayoría de mis compañeros y excompañeros, estaban en una situación muy vulnerable, es cuando se unían. Después de unos meses se van empoderando y, cuando ya tienen cierta confianza, no es fácil que acepten que una mujer esté al frente de ellos, ni de una organización. Eso ha generado conflictos en los que he tenido que decirles que así es. Tengo un poco más de experiencia en esto y voy tratando de hacerlo como van las cosas. Ha sido bastante complicado, porque han querido hacerme a un lado y dejarme fuera.

Deportados Unidos nació conmigo, tiene una visión y una misión. Llegué a ser cuestionada sobre por qué yo tomo las decisiones. Nadie de los deportados había tomado parte del activismo en Estados Unidos. Eso ha sido una de las cosas más difíciles que he pasado: ser una mujer desarrollando un liderazgo, no es bien visto. Al principio cuando ellos llegan en situación vulnerable lo aceptan, pero con los meses te cuestionan por qué tú.

De alguna manera, el colectivo ha cumplido su objetivo de empoderamiento, desarrollo de liderazgo, porque del mismo grupo se hicieron otros colectivos."

Si bien la biografía de Ana Laura sigue en construcción (tanto narrativa como performativamente) hacemos aquí un corte para dejar en evidencia las 
políticas de identidad puestas en juego por Ana Laura y sus compañeros de DUL al autoidentificarse como un grupo vulnerable que no encaja en el perfil de deportado llamado Dreamer. Con sus acciones políticas, latentes o manifiestas, los deportados mayores de 40 años, con familias transnacionales, demandan del Estado y de las instituciones acciones que atiendan y reconozcan sus necesidades. Pero parten del reto de primero hacerse ver ante estas instituciones.

Esta biografía nos desafía a ampliar los imaginarios sobre las implicaciones de las deportaciones en masa de Estados Unidos desde hace más de una década.

\section{A modo de conclusión}

En este ejercicio, cuya columna vertebral es la curaduría de la memoria autobiográfica de Ana Laura López, esbozamos respuestas en clave de narrativa experiencial, que demuestra la centralidad de politizar el lenguaje para comprender y explicar las intersecciones que se producen en torno a políticas de identidad, las respuestas estatales y la crisis de derechos humanos que atraviesan los pueblos en movimiento.

Mostramos que el trabajo de los cuidados replantea las formas jurídicas para la membresía política y la subjetividad jurídica. Este relato demuestra el tránsito urgente de narrativas enclaustradas en el nacionalestadocentrismo, al mismo tiempo que en el nacionalismo metodológico de los discursos en torno a la ciudadanía, para abrir la imaginación teórica y política a formas de cuidadanía transnacional (VALENCIA, 2018), que se derivan de maternar una familia transnacional atravesada por el gobierno global de fronteras, al mismo tiempo que maternar las luchas de migrantes por el derecho a tener derechos (VARELA, 2013a).

La memoria de las voces migrantes apunta que las migraciones incentivan y propician una conciencia de sí entre los sujetos que atraviesan fronteras legales y simbólicas para buscarse una vida que se pueda vivir. Consideramos que tejer memoria migrante en clave de un feminismo migrante, nos permite conocer para interpretar y narrar, acompańando los procesos de mujeres a las que la experiencia exílica las transforma, y nos aporta pistas para el cambio social de los entramados comunitarios en los que estas mujeres habitan.

Usar la memoria de las voces de las migrantes abre brecha para provocar cambios semánticos en las plasticidades del auto y heterorrepresentaciones, en torno a un fenómeno tan complejo como vital: la movilidad humana. Esta curaduría autoetnográfica de la experiencia de Ana Laura López contribuye a los 
estudios sobre las muchas formas de familias actualmente existentes, en contra de percepciones heteronormadas sobre la así llamada "familia nuclear".

Con este ejercicio de hechura colectiva, las autoras queremos demostrar la pertinencia de las apuestas teóricas y metodológicas sobre las identidades sociales y colectivas al feminismo migrante que, de hecho, ejerce ya una crianza atrapada en la transitoriedad perpetua que permite la autodeterminación de las mujeres migrantes, aunque también genera un profundo desgarro exílico en las propias mujeres y sus familias.

Con este ejercicio abonamos a la apuesta de "Nunca más un relato sobre nosotras sin nosotras". Ilustramos que la práctica de muerte del régimen de deportabilidad del gobierno global de las migraciones es resistida, en la vida cotidiana, con prácticas de vida por las mujeres migrantes, deportadas o refugiadas de violencias.

\section{BIBLIOGRAFÍA}

ABREGO, L. Sacrificing families: Navigating laws, labor, and love across borders. Stanford: Stanford University Press, 2014.

ANZALDÚA, G. Borderlands. Madrid: Capitan Swing, 2016.

APPADURAI, A. Traumatic Exit, Identity Narratives, and the Ethics of Hospitality. Television \& New Media, Thousand Oaks, CA, v. 20, n. 6, p.558-565, 2019.

APPADURAI, A. La modernidad desbordada. Buenos Aires: Fondo de Cultura Económica, 2001.

BENHABIB, S. Los derechos de los otros: extranjeros, residentes y ciudadanos. Barcelona: Gedisa, 2005.

BERTAUX, D. Los relatos de vida: perspectiva etnosociológica. Barcelona: Bellaterra, 2005.

DE GENOVA, N.; PEUTZ, N. The Deportation Regime: Sovereignty, Space, and the Freedom of Movement. London: Duke University Press, 2010.

FERRAROTTI, F. Las historias de vida como método. Convergencia, México, v. 14, n. 44, p. 15-40, 2007.

FOUCAULT, M. El orden del discurso. Madrid: Tusquets, 2005.

FOUCAULT, M. La ética del cuidado de uno mismo como práctica de la libertad. In: FOUCAULT, M. Hermenéutica del sujeto. Madrid: Akal, 2001. 
FOUCAUlT, M. El sujeto y el poder. Revista Mexicana de Sociología, Mexico, v. 50, n. 3, p. 3-20, 1988.

FUSCO, C. The other history of intercultural performance. TDR (1988-), Cambridge, v. 38, n.1, p. 143-167, 1994.

GIMÉNEZ, G. Materiales para una teoría de las identidades sociales. Frontera Norte, Tijuana, v. 9, n. 18, p. 9-28, 1997.

GOLUVOB, N. Interseccionalidad. In: MORENO, H.; ALCÁNTARA, E. (coord.). Conceptos clave en los estudios de género. Ciudad de México: CIEG UNAM, 2018. vol. 2. p. 197-213.

GÓMEZ-PEÑA, G. En defensa del arte del performance. Horizontes Antropológicos, Porto Alegre, año 11, n. 24, p. 199-226, 2005.

GROSFOGUEL, R. El concepto de «racismo» en Michel Foucault y Frantz Fanon: ¿Teorizar desde la zona del ser o desde la zona del no-ser?. Tabula rasa, Bogota, n. 16, p. 79-102, 2012.

HERRERA, G. Trabajo doméstico, cuidados y familias transnacionales en América Latina: reflexiones sobre un campo en construcción. Amérique Latine Histoire et Mémoire: Les Cahiers, París, n. 31, 9 jun. 2016.

LOAEZA REYES, L.; CASTAÑEDA, M. P. Identidades: teorías y métodos para su análisis. México: CEICH/ UNAM, 2014.

MEZZADRA, S. Derecho de Fuga: Migraciones, ciudadanía y globalización. Madrid: Traficantes de Sueños, 2004.

PÉREZ OROZCO, A. Subversión feminista de la economía: Aportes para un debate sobre el conflicto capital-vida. Madrid: Traficantes de sueños, 2014.

SUÁREZ-NAVAZ, L.; HERNÁNDEZ, R. A. Descolonizando el feminismo: Teoría y práctica desde los márgenes. Madrid: Ediciones Cátedra, 2008.

UNIDAD DE POLÍTICA MIGRATORIA, REGISTRO E IDENTIDAD DE PERSONAS [UPMRIP]. Boletín mensual de estadísticas migratorias. Ciudad de México: Secretaría de Gobernación, 2019.

UNIDAD DE POLÍTICA MIGRATORIA, REGISTRO E IDENTIDAD DE PERSONAS [UPMRIP]. Boletín mensual de estadísticas migratorias. Ciudad de México: Secretaría de Gobernación, 2010.

VALENCIA, S. El transfeminismo no es un generismo. Pléyade, Santiago de Chile, n. 22, p. 27-43, 2018. 
VARELA, A. Notes for an Anti-racist Feminism in the Wake of the Migrant 20 Caravans. The South Atlantic Quarterly, Durham, v. 119, n. 3, p. 655-663, 2020.

VARELA, A. La trinidad perversa de la que huyen las fugitivas centroamericanas: violencia feminicida, violencia de estado y violencia de mercado. Debate feminista, Ciudad de Mexico, v. 53, p. 1-17, 2017.

VARELA, A. La ciudadanía instituida en la era de la resistencia: El movimiento migrante en Barcelona como agente de nuevos discursos sobre la ciudadanía. In: BOLAÑOS G.; HIPOLITO, B. (coord.). Biopolítica y Migración: El eslabón perdido de la globalización. Ciudad de México: Universidad Autónoma Metropolitana, 2015. p. 261-308.

VARELA, A. Por el derecho a permanecer ya pertenecer: Una sociología de la lucha de los migrantes. Madrid: Traficantes de Sueños, 2013a.

VARELA, A. Del silencio salimos: la Caravana de madres hondureñas en México. Un ejemplo de resistencias en clave femenina al régimen global de fronteras. In: AQUINO, A.; VARELA, A.; DÉCOSSE, F. Desafiando fronteras: Control de la movilidad y experiencias migratorias en el contexto capitalista. México: Surplus Ediciones, 2013b. p.175-186.

VARELA, A. Porque la ciudadanía se consigue ejerciéndola...: Una aproximación sociológica al proceso instituyente del movimiento de migrantes en Barcelona. 2009. Tesis (Doctorado en Sociologia) - Universitat Autònoma de Barcelona, Barcelona, 2009.

VIVEROS, M. La interseccionalidad: una aproximación situada a la dominación. Debate feminista, Ciudad de Mexico, v. 52, p. 1-17, 2016.

Recebido em: 30 de agosto de 2020

Aprovado em: 23 de novembro de 2020 